\title{
A new paradigm is needed to guide the utility of functional electrical stimulation in rehabilitation medicine
}

Received: 17 August, 2020

Accepted: 28 August, 2020

Published: 29 August, 2020

*Corresponding author: Gad Alon, PhD, PT, University of Maryland School of Medicine, Baltimore, MD, USA, Tel: 240-644-8611; E-mail: GAlon@som.umaryland.edu

Keywords: Independence; Functional electrical stimulation; Paradigm, Rehabilitation medicine https://www.peertechz.com

Check for updates

\section{Gad Alon*}

University of Maryland School of Medicine, Baltimore, MD, USA

\begin{abstract}
Back in 2006, an invited commentary raised the question "are we asking clinically relevant questions"? The commentary referenced an application of electrical stimulation in a clinical trial [1]. This question regarding Neuromuscular Electrical Stimulation (NMES) and Functional Electrical Stimulation (FES) is as relevant in 2020. Based on the premise and presumption that the aim of applying NMES/FES is to enable each patient achieve the most effective and efficient recovery of functional independence, one must wonder if we are asking the most critical, yet clinically relevant questions? This perspective focuses on locomotion and upper extremity function following a Cerebrovascular Accident (CVA) and non-neurological damage to the knee joint. It delineates several questions elaborating on the issue of meaningful outcomes to the patients versus the focus of clinician and researchers on measurable outcomes. It offers pathways that should hopefully lead to considerably more effective and efficient utilization of NMES and FES in rehabilitation medicine.
\end{abstract}

\section{Perspective}

This perspective is written to highlight a concern that current physical rehabilitation treatment options offered to patients recovering from damage to the brain, do not meet many patients' expectations. The paper is limited in scope to stroke survivors using only selected references, but the readers are encouraged to extrapolate and extend the perspective to other patients needing physical rehabilitation including but not limited to cerebral palsy, multiple sclerosis, and musculoskeletal degenerative joint disease.

\section{Locomotion}

The question of clinical relevance has been addressed in the rehabilitation literature numerous times including by asking patients how they perceive the effects of an intervention [2]. But the issue of who determines whether an outcome is relevant to the patient remains unresolved. Clinical researchers focusing on locomotion typically select, if available, objective, measurable, and previously validated outcome measures. Among them are walking distance and speed [3], timed-Up and go (TUG) [4], or five-times stand up and sit down $[5,6]$ tests, representing recovery of basic locomotion ability. Yet the question remains: are objective, statistically significant improvement of 35-50 meters of walking distance, or improved walking speed by $0.15-0.2$ meter/sec [7-9] are also perceived by the study's patients as improved locomotion ability? The answer is frequently not, according to several scientific publications [10-12].

Whether researchers measure impairments or functional outcomes associated with locomotion or upper extremity use in daily activities, prediction models such as reported by Wand, et al. [4] were limited to identifying responders and non-responders based on motivation and functional status prior to stroke. Models that predict which patient will recover independence in daily function could not be found in peerreviewed publications. The inevitable question is therefore: what outcome measures are critical to the patient, not to the researchers-clinicians? [13]. To answer this question there is a need to re-examine what happen to a person that suddenly loses control over the ability to move one or more body parts.

One governing foundation of physical rehabilitation is that human beings hope to remain independent of any form of 
assistance in executing daily functions. These include but are not limited to walking, standing up and sitting down, as well as negotiating uneven terrain. Becoming depended on technology driven assistive devices, and worse on human assistance, reflect successive and sometimes abrupt loss of locomotion independence. Accordingly, a patient who became dependent on human assistance to ambulate or stand up, and following physical rehabilitation no longer need human assistance is likely to perceive the therapy as yielding meaningful improvement. Similarly, a patient who ambulate with hand support using a walker, quad-cane or a cane and after training no longer needs hand support to walk is likely to report a treatment-enhanced meaningful achievement. The same is true for a patient who depends of FES to walk better and after 6-12 months no longer need the FES during ambulation. These are examples of objective, measurable outcomes that are likely to be perceived a success by most patients but unfortunately are rarely, if ever, reported in published clinical investigations. Moreover, these patients' reported changes in outcomes should be primary not secondary or tertiary outcomes in future clinical trials.

To focus on the contribution of FES in the attempt to help patients become independent in locomotion, the primary muscle groups that are likely to benefit from stimulation during standing up and sitting down are the plantar flexors, the quadriceps, and to a lesser extent the hamstrings and dorsiflexors. The need to stimulate these muscles is implied based on well-established biomechanical data that these muscles are the prime physiological torque generators of transitioning from sitting to standing and back to sitting [14]. When the damage is not to the brain but to the musculo-skeletal system such as following repair of the torn anterior cruciate ligament (ACL) or following total knee joint replacement (TKA), the primary loss of strength and motor control are in the quadriceps and hamstrings [15]. Following brain damage, these muscles become weak and atrophied and the patient loses cortical and sub-cortical control over the magnitude and timing of contraction during locomotion [16]. Ambulation is somewhat different than standing up and sitting down. When the damage is to the brain, the likely muscles to benefit from FES during walking are the dorsiflexors, plantarflexors, and hamstring [17]. Following repair of the knee's ligaments or post knee joint replacement, stimulation the quadriceps and hamstring during walking should be considered [18].

The long-term goal of the locomotion training post stroke should be to initiate FES as early as possible and continue using it daily until independent locomotion is achieved so that the patient no longer needs the support of FES to stand-sit and walk. Considering patients without damage to the brain, some $35-40 \%$ of patients recovering from reconstructive knee surgeries are expected to benefit from FES/NMES from 4 to 12 months to reach the long-term goal $[19,20]$. Regrettably, there is no current documented evidence how many stroke survivors are expected to reach the goal of no longer depending on FES to ambulate. One study from 1997 reported that only 3 of 50 patients post-stroke have reached this goal [21]. The critically relevant clinical question is why so few? One plausible hypothesis implicates the "open-loop" design of commercially available FES systems [22]. For example, having pre-determined stimulation intensities to induce contraction of the dorsiflexors may result in "over-stimulation", thus reducing the need for the brain's motor drive to control the activation of these muscles. To transfer control from the FES to the brain, closed-loop designs have been suggested where the stimulation is only added to complete the desired joint range of motion that the patient is unable to complete without stimulation [23]. However, such closed-loop control FES systems are only available to few research groups. Whether it will lead to more patients reaching the goal of becoming FES independent remain unknown until these systems become commercially available.

\section{Upper extremity functions}

Typical functions of the upper extremities include the ability to unimanually or bimanually grasp, hold, move, release, and manipulate objects. Numerous clinical researchers favor validated scales to asses recovery of daily use of the paretic upper extremity. Among these scales are the FuglMeyer assessment (FMA) [24,25], the Wolf Motor Assessment (WMA) $[26,27]$ or the Action Research Arm Test (ARAT) [2833]. Unfortunately, statistically significant improvement of these scales did not translate to actual daily functional use of the paretic upper extremity, once the studies were completed $[34,35]$. Furthermore, one study of stroke survivors calculated the residual deficit (RD) of some of these measures as a mean of identifying the limit of recovery after 12 weeks of intensive training of the upper extremity. The data confirmed that for many, the recovery was very limited [36].

Similar to locomotion, a critically relevant clinical question facing researchers and clinicians is what constitute recovery of hand function following damage to the brain? Depending on the definition, about $80-85 \%$ of stroke survivors will not recover sufficient upper extremity movements and dexterity to resume independent use of the paretic extremity in daily activity. This reality hold true even after completing training that include bimanual activities and extended treatment dose $[37,29]$. Moreover, improvement in the above mentioned scales is typically measured as time (sec) of task completion, not the ability to regain use the paretic hand in unimanual or bimanual daily functions once the study is over. As a result, these patients' realistic goal should be to use the paretic extremity as an assisting, not primary hand in daily functions and the training program should be restructured accordingly. Clinical data confirm that while using the FES many patients can achieve such a goal provided they have a self-administered FES used in the home environment $[38,39]$. The anecdotal patients seen on the web video media using FES applied to the paretic upper extremity appear to depend on the FES to perform different tasks. But the critical and clinically relevant question is therefore: can FES be used to train the patient so eventually they will use the paretic hand to assist in carrying objects, and helping in bimanual daily functions without FES? Currently, answer to this question could not be found in peerreviewed publications. 
Few published studies where FES was used in a clinical setting to train the upper extremity, did not report how many, or if any patient who completed training was able to use the paretic upper extremity as assistive hand in her/his home environment without FES [40-42]. Thus, the relevant question is: what technological advancements and training programs are needed so patients become independent using the upper extremity at home? Unlike the lower extremity [43], wearable wireless FES systems are not commercially available for the upper extremity. Moreover, deciding which muscle groups require FES to be able to reach, open the hand, grasp, move and release an object is less predictive than in the lower extremity for several reasons. Variability in patients paresis/paralysis presentation and upper extremity position as well as distance from the object, are some of the reasons [44]. In addition, there is a breakdown in the continuum of care of upper extremity rehabilitation where FES training is only offered for 4-6 weeks and at most for 12 weeks [42]. Considered collectively, it appears that a paradigm shift should be considered if the aim is to maximize the recovery of upper extremity function following damage to the brain.

\section{Summary}

This perspective focus on achieving successful outcomes as perceived by patients recovering from damage to the brain or the musculo-skeletal system of the knee joint and contrast them with successful outcomes recommended by clinicians and researchers. The emphasis is on the contribution of non-invasive Functional Electrical Stimulation (FES) to the recovery of independence in locomotion and upper extremity functions. Embedded in the perspective is the suggestion that re-examining both technological and clinical training paradigms will be needed if the goal is to achieve independence in activities of daily living. The suggested paradigms include reprioritization of clinical outcome measures to reflect progress toward recovering independence and the use of closed-loop FES systems to minimize "over stimulation". The closed-loop FES is projected to help transfer of control from the FES induced muscle activation to the brain's motor drive controlling these muscles.

\section{References}

1. Alon G (2006) Electrical stimulation in cerebral palsy: are we asking clinically relevant questions? Dev Med Child Neurol 48: 868. Link: https://bit.ly/3Ir7zyB

2. Nascimento LR, Ada L, Rocha GM, Teixeira-Salmela LF (2019) Perceptions of individuals with stroke regarding the use of a cane for walking: A qualitative study. J Bodyw Mov Ther 23: 166-170. Link: https://bit.ly/2G9w43

3. Brown AW, Therneau TM, Schultz BA, Niewczyk PM, Granger CV (2015) Measure of functional independence dominates discharge outcome prediction after inpatient rehabilitation for stroke. Stroke 46: 1038-1044. Link: https://bit.ly/3jqs90a

4. Wang YH, Yang YR, Pan PJ, Wang RY (2014) Modeling factors predictive of functional improvement following acute stroke. J Chin Med Assoc 77: 469476. Link: https://bit.ly/3b9linK

5. Millor N, Lecumberri P, Gomez M, et al. (2017) Gait Velocity and Chair Sit Stand-Sit Performance Improves Current Frailty-Status Identification. IEEE Trans Neural Syst Rehabil Eng 25: 2018-2025. Link: https://bit.ly/3bb1VMy
6. Doheny EP, Walsh C, Foran T, Greene BR, Fan CW, et al. (2013) Falls classification using tri-axial accelerometers during the five-times-sit-to-stand test. Gait Posture 38: 1021-1025. Link: https://bit.ly/2EsYSDy

7. Mehrholz J, Pohl M, Kugler J, Elsner B (2018) The Improvement of Walking Ability Following Stroke. Dtsch Arztebl Int 115: 639-645. Link: https://bit.ly/3gClBdi

8. Graham SA, Roth EJ, Brown DA (2018) Walking and balance outcomes for stroke survivors: a randomized clinical trial comparing body-weight-supported treadmill training with versus without challenging mobility skills. J Neuroeng Rehabil 15: 92. Link: https://bit.ly/2YI47WW

9. Askim T, Dahl AE, Aamot IL, Hokstad A, Helbostad J, et al. (2014) High-intensity aerobic interval training for patients 3-9 months after stroke: a feasibility study. Physiother Res Int 19: 129-139. Link: https://bit.ly/3hESil5

10. Krishnan S, Hay CC, Pappadis MR, Deutsch A, Reistetter TA (2019) Stroke Survivors' Perspectives on Post-Acute Rehabilitation Options, Goals, Satisfaction, and Transition to Home. J Neurol Phys Ther 43: 160-167. Link: https://bit.ly/2Ddnlfo

11. Rice DB, Mclntyre A, Mirkowski M, Janzen S, Viana R, et al. (2017) PatientCentered Goal Setting in a Hospital-Based Outpatient Stroke Rehabilitation Center. PM R 9: 856-865. Link: https://bit.ly/2QAr7SZ

12. Groeneveld IF, Goossens PH, van Braak I, van der Pas S, Meesters JJL, et al. (2019) Patients' outcome expectations and their fulfilment in multidisciplinary stroke rehabilitation. Ann Phys Rehabil Med 62: 21-27. Link: https://bit.ly/31F5pU4

13. Bohannon RW, Horton MG, Wikholm JB (1991) Importance of four variables of walking to patients with stroke. Int J Rehabil Res 14: 246-250. Link: https://bit.ly/3jmF1EE

14. Brown M, Sinacore DR, Host HH (1995) The relationship of strength to function in the older adult. J Gerontol A Biol Sci Med Sci 50 Spec No:55-59. Link: https://bit.ly/3jkEdAO

15. Thomas AC, Villwock M, Wojtys EM, Palmieri-Smith RM (2013) Lower Extremity Muscle Strength After Anterior Cruciate Ligament Injury and Reconstruction. J Athl Train 48: 610-620. Link: https://bit.ly/3jqWOL6

16. Lodha N, Chen YT, McGuirk TE, Fox EJ, Kautz SA, et al. (2017) EMG synchrony to assess impaired corticomotor control of locomotion after stroke. Electromyogr Kinesiol 37: 35-40. Link: https://bit.ly/2Qx2W80

17. Springer S, Laufer Y, Becher M, Vatine JJ (2013) Dual-channel functional electrical stimulation improvements in speed-based gait classifications. Clin Interv Aging 8: 271-277. Link: https://bit.ly/34GKcLC

18. Moran U, Gottlieb U, Gam A, Springer S (2019) Functional electrical stimulation following anterior cruciate ligament reconstruction: a randomized controlled pilot study. J Neuroeng Rehabil 16: 89. Link: https://bit.ly/3lnmvOe

19. Pua YH, Seah FJ, Poon CL, Tan JW, Alan Clark R, et al. (2018) Age- and sexbased recovery curves to track functional outcomes in older adults with total knee arthroplasty. Age Ageing 47: 144-148. Link: https://bit.ly/2Z1zLPh

20. Pua YH, Seah FJ, Clark RA, Lian-Li Poon C, Tan JW, et al. (2017) Factors associated with gait speed recovery after total knee arthroplasty: A longitudina study. Semin Arthritis Rheum 46: 544-551. Link: https://bit.ly/3gHUNbo

21. Burridge J, Taylor P, Hagan S, Swain I (1997) Experience of clinical use of the Odstock dropped foot stimulator. Artif Organs. 21: 254-260. Link: https://bit.ly/32youqx

22. Alon G (2018) Functional Electrical Stimulation (FES): Clinical successes and failures to date. J Nov Physiother Rehabil 2: 80-86. Link: https://bit.ly/3b4GiO

23. Rodgers MM, Alon G, Pai VM, Conroy RS (2019) Wearable technologies for active living and rehabilitation: Current research challenges and future opportunities. J Rehabil Assist Technol Eng 6: 2055668319839607. Link: https://bit.ly/32ymzS

Citation: Alon G (2020) A new paradigm is needed to guide the utility of functional electrical stimulation in rehabilitation medicine. J Nov Physiother Phys Rehabil 7(2): 045-048. DOI: https://dx.doi.org/10.17352/2455-5487.000078 
24. Kiper P, Szczudlik A, Agostini M, Opara J, Nowobilski R, et al. (2018) Virtual Reality for Upper Limb Rehabilitation in Subacute and Chronic Stroke: A Randomized Controlled Trial. Arch Phys Med Rehabil 99: 834-842 e834. Link: https://bit.ly/2YJOGNO

25. Turolla A, Dam M, Ventura L, Tonin P, Agostini M, et al. (2013) Virtual reality for the rehabilitation of the upper limb motor function after stroke: a prospective controlled trial. J Neuroeng Rehabil 10: 85. Link: https://bit.ly/32zY33M

26. Busching I, Sehle A, Sturner J, Liepert J (2018) Using an uppe extremity exoskeleton for semi-autonomous exercise during inpatient neurological rehabilitation- a pilot study. J Neuroeng Rehabil 15: 72. Link: https://bit.ly/2G1MCdm

27. Kagawa S, Koyama T, Hosomi M, Takebayashi T, Hanada K, et al. (2013) Effects of constraint-induced movement therapy on spasticity in patients with hemiparesis after stroke. J Stroke Cerebrovasc Dis 22: 364-370. Link: https://bit.ly/3gCMPAn

28. Zhao JL, Chen PM, Zhang T, Li H, Lin Q, et al. (2019) Inter-rater and Intra-rater Reliability of the Chinese Version of the Action Research Arm Test in People With Stroke. Front Neurol 10: 540. Link: https://bit.ly/34KYqeC

29. Smith MC, Ackerley SJ, Barber PA, Byblow WD, Stinear CM (2019) PREP2 Algorithm Predictions Are Correct at 2 Years Poststroke for Most Patients. Neurorehabil Neural Repair 33: 635-642. Link: https://bit.ly/2QBnXhW

30. Choudhury S, Shobhana A, Singh R, Sen D, Anand SS, et al. (2019) The Relationship Between Enhanced Reticulospinal Outflow and Upper Limb Function in Chronic Stroke Patients. Neurorehabil Neural Repair 33: 375-383. Link: https://bit.ly/2Eu6XI9

31. Cherpin A, Kager S, Budhota A, Contu S, Vishwanath D, et al. (2019) A preliminary study on the relationship between proprioceptive deficits and motor functions in chronic stroke patients. IEEE Int Conf Rehabil Robot 2019 465-470. Link: https://bit.ly/3lvnf44

32. Antoniotti P, Veronelli L, Caronni A, Monti A, Aristidou E, et al. (2019) No evidence of effectiveness of mirror therapy early after stroke: an assessorblinded randomized controlled trial. Clin Rehabil 33: 885-893. Link: https://bit.ly/2EFisvT

33. Zariffa J, Myers M, Coahran M, Wang RH (2018) Smallest real differences for robotic measures of upper extremity function after stroke: Implications for tracking recovery. J Rehabil Assist Technol Eng 5: 2055668318788036. Link: https://bit.ly/2QBKo6s

34. Demir YP, Balci NC, Unluer NO, Uluğ N, Dogru E, et al. (2015) Three different points of view in stroke rehabilitation: patient, caregiver, and physiotherapist Top Stroke Rehabil 22: 377-385. Link: https://bit.ly/2QCcleG

35. Kwon BK, Hillyer J, Tetzlaff W (2010) Translational research in spinal cord injury: a survey of opinion from the SCI community. J Neurotrauma 27: 21-33. Link: https://bit.ly/31B9yZp

36. Alon G (2009) Defining and measuring residual deficits of the upper extremity following stroke: a new perspective. Top Stroke Rehabil 16: 167-176. Link: https://bit.ly/32DUCc2

37. Knutson JS, Makowski NS, Harley MY, et al. (2020) Adding Contralaterally Controlled Electrical Stimulation of the Triceps to Contralaterally Controlled FES of the Finger Extensors Reduces Upper Limb Impairment and Improves Reachable Workspace but not Dexterity: A Randomized Controlled Trial. Am J Phys Med Rehabil 99: 514-521. Link: https://bit.ly/31CaSuT

38. Alon G (2013) Functional Electrical Stimulation (FES): Transforming Clinica Trials to Neuro-Rehabilitation Clinical Practice- A Forward Perspective. Journal of Novel Physiotherapies 3. Link: https://bit.ly/34HrcfR

39. Alon G, McBride K (2003) Persons with C5 or C6 tetraplegia achieve selected functional gains using a neuroprosthesis. Arch Phys Med Rehabil 84: 119-124. Link: https://bit.ly/3gz9L3u

40. Wilson RD, Page SJ, Delahanty M, Knutson JS, Gunzler DD, et al. (2016) UpperLimb Recovery After Stroke: A Randomized Controlled Trial Comparing EMGTriggered, Cyclic, and Sensory Electrical Stimulation. Neurorehabil Neura Repair 30: 978-987. Link: https://bit.ly/3jjkO2u

41. Page SJ, Levin L, Hermann V, Dunning K, Levine P (2012) Longer versus shorter daily durations of electrical stimulation during task-specific practice in moderately impaired stroke. Arch Phys Med Rehabil 93: 200-206. Link: https://bit.ly/3gAe5zn

42. Alon G, Levitt AF, McCarthy PA (2007) Functional electrical stimulation enhancement of upper extremity functional recovery during stroke rehabilitation: a pilot study. Neurorehabil Neural Repair 21: 207-215. Link: https://bit.ly/3hLclVG

43. Springer S, Vatine JJ, Wolf A, Laufer Y (2013) The effects of dual-channe functional electrical stimulation on stance phase sagittal kinematics in patients with hemiparesis. J Electromyogr Kinesiol 23: 476-482. Link: https://bit.ly/3jnOpba

44. Lang CE, Waddell KJ, Klaesner JW, Bland MD (2017) A Method for Quantifying Upper Limb Performance in Daily Life Using Accelerometers. J Vis Exp 21 55673. Link: https://bit.ly/3jkG5Zy

Discover a bigger Impact and Visibility of your article publication with

Peertechz Publications

Highlights

* Signatory publisher of ORCID

* Signatory Publisher of DORA (San Francisco Declaration on Research Assessment)

* Articles archived in worlds' renowned service providers such as Portico, CNKI, AGRIS, TDNet, Base (Bielefeld University Library), CrossRef, Scilit, J-Gate etc.

* Journals indexed in ICMJE, SHERPA/ROMEO, Google Scholar etc.

* OAI-PMH (Open Archives Initiative Protocol for Metadata Harvesting)

- Dedicated Editorial Board for every journal

* Accurate and rapid peer-review process

* Increased citations of published articles through promotions

* Reduced timeline for article publication

Submit your articles and experience a new surge in publication services (https://www.peertechz.com/submission).

Peertechz journals wishes everlasting success in your every endeavours.

Copyright: (c) 2020 Alon G. This is an open-access article distributed under the terms of the Creative Commons Attribution License, which permits unrestricted use distribution, and reproduction in any medium, provided the original author and source are credited.

Citation: Alon G (2020) A new paradigm is needed to guide the utility of functional electrical stimulation in rehabilitation medicine. J Nov Physiother Phys Rehabil 7(2): 045-048. DOI: https://dx.doi.org/10.17352/2455-5487.000078 